\title{
Insulinotropic agent ID-1101 (4-hydroxyisoleucine) activates insulin signaling in rat
}

\author{
Christophe Broca, ${ }^{1,2}$ Vincent Breil, ${ }^{3}$ Céline Cruciani-Guglielmacci, ${ }^{5}$ Michèle Manteghetti, ${ }^{1}$ \\ Christine Rouault, ${ }^{3}$ Michel Derouet, ${ }^{4}$ Salwa Rizkalla, ${ }^{3}$ Bernard Pau, ${ }^{1}$ Pierre Petit, ${ }^{1}$ \\ Gérard Ribes, ${ }^{1}$ Alain Ktorza, ${ }^{5}$ René Gross, ${ }^{1}$ Gérard Reach, ${ }^{3}$ and Mohammed Taouis ${ }^{4}$ \\ ${ }^{1}$ Laboratoire de Pharmacologie, Centre de Pharmacologie et Biotechnologies pour la Santé-Unite Mixte de Recherche 5160 \\ Centre National de la Recherche Scientifique, Faculté de Médecine, 34060 Montpellier; ${ }^{2}$ INNODIA S.A., 34000 Montpellier; \\ ${ }^{3}$ Institut National de la Santé et de la Recherche Médicale U341, Service de Diabétologie, 75004 Paris; \\ ${ }^{4}$ Laboratoire de Biologie Cellulaire et Moléculaire, bâtiment des Biotechnologies, Institut National \\ de la Recherche Agronomique, 78352 Jouy-en-Josas; and ${ }^{5}$ Laboratoire de Physiopathologie de la Nutrition, \\ Centre National de la Recherche Scientifique UMR 7059, Université Paris 7, 75005 Paris, France
}

Submitted 11 April 2003 ; accepted in final form 2 March 2004

Broca, Christophe, Vincent Breil, Céline Cruciani-Guglielmacci, Michèle Manteghetti, Christine Rouault, Michel Derouet, Salwa Rizkalla, Bernard Pau, Pierre Petit, Gérard Ribes, Alain Ktorza, René Gross, Gérard Reach, and Mohammed Taouis. Insulinotropic agent ID-1101 (4-hydroxyisoleucine) activates insulin signaling in rat. Am J Physiol Endocrinol Metab 287: E463-E471, 2004. First published April 13, 2004; 10.1152/ajpendo.00163.2003.— ID-1101 (4-hydroxyisoleucine), an amino acid extracted from fenugreek seeds, exhibits an interesting glucose-dependent insulinstimulating activity. The present study was undertaken to investigate a possible extrapancreatic effect of ID-1101 on insulin signaling and action besides its previously described insulinotropic action. Insulinsensitizing effects of ID-1101 were investigated in rat in vivo by three different approaches: 1) using euglycemic hyperinsulinemic clamps in two different rat models of insulin resistance, i.e., Zucker $f a / f a$ rats and rats fed a sucrose-lipid diet; 2) measuring liver and muscle phosphatidylinositol (PI) 3-kinase activity after an acute injection of ID-1101 in normal and insulin-resistant diabetic rats; and 3) after chronic treatment in two rat models of insulin resistance. Euglycemic hyperinsulinemic clamp experiments revealed that ID-1101 can improve insulin resistance through an increase of peripheral glucose utilization rate in sucrose-lipid-fed rats and by decreasing hepatic glucose production in Zucker fa/fa rats. Moreover, we demonstrated that a single injection of ID-1101 activates the PI 3-kinase activity in liver and muscle from normal rats but also in muscle from diabetic rats. Finally, chronic ID-1101 treatment significantly reduced insulinemia in type 2 diabetic rats and reduced the progression of hyperinsulinemia in insulin-resistant obese Zucker $f a / f a$ rats. These findings clearly demonstrate that ID-1101 can reduce insulin resistance through activation of the early steps of insulin signaling in peripheral tissues and in liver. In summary, ID-1101, besides its insulinotropic effect, directly improves insulin sensitivity, making it a potentially very valuable therapeutic agent for diabetes treatment.

insulin resistance; phosphatidylinositol 3-kinase; euglycemic hyperinsulinemic clamp; diabetes; obesity

TYPE 2 DIABETES, the most common metabolic disorder affecting more than $5 \%$ of the population in western countries, is characterized by a combination of pancreatic $\beta$-cell impaired insulin secretion and hepatic and peripheral insulin resistance

Address for reprint requests and other correspondence: C. Broca, Laboratoire de Pharmacologie, CPBS-UMR 5160 CNRS, Faculté de Médecine, Institut de Biologie, Boulevard Henri IV, 34060 Montpellier cedex 1, France (E-mail: christophe.broca@univ-montp1.fr).
$(7,14)$. An early abnormality in type 2 diabetes pathogenesis is insulin resistance, which usually precedes the development of glucose intolerance. During this period, the pancreas attempts to compensate for insulin resistance by increasing insulin secretion, but once pancreatic $\beta$-cells are unable to maintain a high circulating level of insulin, diabetes ensues.

Insulin resistance refers to a decreased capacity of insulin to regulate nutrient metabolism and particularly glucose uptake and metabolism in target tissues such as skeletal muscle and adipose tissue. At the molecular level, insulin binding to its membrane receptor triggers two major kinase cascades, namely the phosphatidylinositol (PI) 3-kinase and MAP kinase pathways that mediate the metabolic and mitogenic effects of insulin, respectively (32). Recent studies have shown that insulin resistance is most likely attributed to a defect in the insulin receptor/insulin receptor substrate-1 (IRS-1)/PI 3-kinase cascade initiated by the Ser/Thr phosphorylation of IRS-1 (13). This phosphorylation inhibits insulin-stimulated tyrosine phosphorylation of IRS- 1 and its ability to bind and activate PI 3-kinase. Moreover, recent data suggest that, besides IRS-1, other IRS proteins such as IRS-2 could play an important tissue-specific role in mediating the effect of insulin on glucose metabolism (23).

Therefore, to prevent long-term complications associated with hyperglycemia in type 2 diabetes, ideal new therapeutic approaches should address defects in both pancreatic insulin secretion and peripheral insulin action. The search for new natural or chemically engineered molecules presenting these properties is of great interest for diabetes treatment.

2S-3R-4S 4-hydroxyisoleucine, or ID-1101, is an amino acid extracted from the seeds of fenugreek (Trigonella foenum graecum L.), a plant traditionally used to treat diabetes. ID-1101 is found exclusively in the fenugreek plant and is not present in mammalian tissues. In previous studies, we have shown that ID-1101 exhibits in vitro an interesting glucose-dependent insulin-releasing activity during static incubations of isolated rat islets (6) as well as in the isolated rat pancreas and incubated human islets (27). Furthermore, acute in vivo administration of ID-1101 improves glucose-stimulated insulin secretion in normal rat

The costs of publication of this article were defrayed in part by the payment of page charges. The article must therefore be hereby marked "advertisement" in accordance with 18 U.S.C. Section 1734 solely to indicate this fact. 
and dog, whereas a short-term treatment improves insulin secretion, increases glucose tolerance, and reduces hyperglycemia in a moderate type 2 diabetic rat model (5). These antidiabetic properties were first ascribed to ID-1101's insulinotropic effect. However, a possible insulin-sensitizing effect of ID-1101 has never been investigated.

In this respect, it must be mentioned that classical branchedchain amino acids such as leucine have been demonstrated to modulate insulin action on signaling of both protein and glucose metabolism $(21,29)$. Moreover, fenugreek seed powder has been shown to restore altered gluconeogenic enzyme activity and to improve glucose homeostasis in alloxan-induced type 1 diabetic animals $(24,25)$. Therefore, the present study was undertaken to evaluate a possible insulin-sensitizing effect of ID-1101 in addition to its insulinotropic action. We first used the gold standard model for the measurement of insulin sensitivity, i.e., the hyperinsulinemic euglycemic clamp, in combination with the infusion of $\left[{ }^{3} \mathrm{H}\right]$ glucose tracers to assess the rate of glucose turnover. Then, to get a first insight into the mechanism involved, we investigated the effect of an acute in vivo injection of ID-1101 on PI 3-kinase activity. Finally, the insulin-sensitizing effect of ID-1101 was tested in two different rat models of insulin resistance, i.e., the mildly diabetic NA + STZ (nicotinamide + streptozotocin) rat with moderate insulin resistance and the obese hyperinsulinemic Zucker fa/fa rat, with a much more severe insulin resistance, to cover the great heterogeneity of insulin resistance states.

\section{MATERIALS AND METHODS}

Chemicals. 2S-3R-4S 4-hydroxyisoleucine (ID-1101) was provided by a pilot plant extraction performed by the group of Prof. Y. Sauvaire (Laboratoire de Recherche sur les Substances Naturelles Végétales, Université Montpellier II, Montpellier, France). Regular insulin was Actrapid (Novo Nordisk). $\left[{ }^{125} \mathrm{I}\right]$ iodine and $\left[{ }^{33} \mathrm{P}\right] \mathrm{ATP}$ were purchased from Amersham France (Les Ulis, France). STZ, NA, albumin (BSA fraction V, radioimmunoassay grade), PMSF, leupeptin, aprotinin, protein A-agarose, and PI were purchased from Sigma Chemical (St. Louis, MO).

Euglycemic hyperinsulinemic clamp studies. In a first set of experiments, 4-wk-old male Sprague-Dawley rats (Janvier, Le Genest Saint Isle, France) were acclimated for 10 days at $22^{\circ} \mathrm{C}$ on a $12: 12-\mathrm{h}$ light-dark cycle with free access to water and standard powder diet. They were then randomized into two groups of 18 animals, receiving one of two experimental powder diets (INRA UPAE, Jouy en Josas, France) for $3 \mathrm{wk}: 1$ ) standard diet (StD) or 2) sucrose-lipid diet (SLD). In SLD, starch was replaced with sucrose, and the lipid content of the diet was increased from 55 to $132 \mathrm{~g} / \mathrm{kg}$. In previous studies, we showed that this SLD induces insulin resistance, given that the area under the curve (AUC) of glycemia during an intraperitoneal glucose tolerance test is unchanged, whereas the AUC of insulinemia is twofold higher than that observed in standard diet rats (1). SLD rats are also known to present an increase in the weight of the liver and the retroperitoneal adipose tissue, hypertriglyceridemia, and an increase in circulating free fatty acids $(1,9)$. Moreover, increases in body weight were not statistically different with either diet [from $249 \pm 5$ to $399 \pm 7 \mathrm{~g}(n=12)$ and $250 \pm 4$ to $411 \pm 9 \mathrm{~g}(n=12)$ for rats fed StD and SLD diets, respectively].

Before the clamp experiment, fed rats were anesthetized with halothane (2\%) vehicled by $\mathrm{N}_{2} \mathrm{O}-\mathrm{O}_{2}(50: 50)$ at a rate of $2 \mathrm{l} / \mathrm{min}$ for 2 rats (Harvard Apparatus, Les Ulis, France). The right jugular vein (silicone tubing ID 0.20 in., OD 0.37 in., A-M-Systems, Carlsborg, WA) and the left carotid artery (polyethylene tubing, ID 0.23 in., OD 0.38 in.) were catheterized for infusion and blood sampling, respec- tively. During the experiment, animals were kept under a lamp, and body temperature was monitored and maintained at $36-37.5^{\circ} \mathrm{C}$. At the end of the surgery, the concentration of halothane and the vehicle gas debit were reduced to $1 \%$ and $11 / \mathrm{min}$ and were kept at these levels until the end of the clamp.

A sequential euglycemic hyperinsulinemic clamp study combined with $\left[{ }^{3} \mathrm{H}\right]$ glucose infusion was then performed $1 \mathrm{~h}$ after the end of the surgical procedure (15), i.e., at 12:00 noon $\left(t_{\mathrm{o}}\right)$ in rats fasted from 09:00 AM, in absence or presence of ID-1101. A 200- $\mu$ l blood sample was taken to determine the initial arterial blood glucose and insulin concentrations. The method was modified to investigate glucose metabolism in basal and in hyperinsulinemic conditions in the same anesthetized animal. For the basal condition, a constant infusion of $\left[{ }^{3} \mathrm{H}\right]$ glucose (NEN Life Sciences) at a rate of $0.1 \mu \mathrm{Ci} / \mathrm{min}$ was started after a priming injection of $5 \mu \mathrm{Ci}$ of radioactive glucose. Blood was sampled at 40, 45, and $50 \mathrm{~min}$ after the start of the infusion to determine blood glucose specific activity and plasma insulin concentration. At the end of this basal period, insulin $\left(0.4 \mathrm{U} \cdot \mathrm{kg}^{-1} \cdot \mathrm{h}^{-1}\right)$ and glucose tracer $(0.1 \mu \mathrm{Ci} / \mathrm{min})$ were infused in saline buffer at a constant rate of $20 \mu \mathrm{l} / \mathrm{min}$ in the jugular vein. Every $5 \mathrm{~min}$, a drop of blood was taken from the tail vein, and glucose concentrations were further determined. From the result, the exogenous glucose infusion rate was adjusted to maintain euglycemia. Ninety minutes after the start of insulin infusion, when the glucose infusion rate was stable for $\geq 20 \mathrm{~min}$, three blood samples were collected within $10 \mathrm{~min}$ to determine blood glucose specific activity and plasma insulin concentration.

To investigate the effects of ID-1101 on insulin sensitivity, StD and SLD animals were further randomized into two groups, the clamp being performed in the presence or in the absence of ID-1101. In the ID-1101-treated groups of rats, a 10-mg priming dose of ID-1101 dissolved in $300 \mu \mathrm{l}$ of $0.9 \% \mathrm{NaCl}$ was administered intravenously at $t_{\mathrm{o}}$, followed by an intravenous infusion of the amino acid at 20 $\mathrm{mg} \cdot \mathrm{kg}^{-1} \cdot \mathrm{h}^{-1}$ throughout the clamp. The control group was treated with a bolus and infusion of an equivalent volume of saline.

Blood glucose concentration was determined using a glucometer (Glucotrend Premium, Roche). Blood samples for determination of glucose specific activity were deproteinized with $\mathrm{Ba}(\mathrm{OH})_{2}-\mathrm{ZnSO}_{4}$ and immediately centrifuged. An aliquot of the supernatant was evaporated in a dessicator to remove tritiated water. The dry residue was dissolved in $0.25 \mathrm{ml}$ of distilled water and counted with $10 \mathrm{ml}$ of scintillation solution (Lumasafe, Packard). Glucose utilization rate (GUR) was calculated according to the formula GUR $=\left[{ }^{3} \mathrm{H}\right]$ glucose infusion rate (GIR) [disintegrations per minute $(\mathrm{dpm}) \cdot \mathrm{min}^{-1} \cdot \mathrm{kg}^{-1}$ ] divided by blood glucose specific activity (dpm/mg) (17). In the basal state, hepatic glucose production (HGP) $=$ GUR, and in clamp period, HGP $=$ GUR - GIR. In this set of experiments, plasma insulin was measured by ELISA (Elit Kit, Eurobio).

A second set of euglycemic hyperinsulinemic clamp studies was performed in Zucker $f a / f a$ rats (Iffa-Credo, L'Arbresle, France), a widely used model of normoglycemic obesity associated with severe insulin resistance and hyperinsulinemia. Seven-week-old rats weighing $\sim 250 \mathrm{~g}$ were used. The protocol was nearly the same as above. Anesthesia was performed using ketamine ( $125 \mathrm{mg} / 100 \mathrm{~g}$ body wt ip). The effect of ID-1101 was studied on glucose turnover under basal and euglycemic hyperinsulinemic clamp conditions by using two different groups of rats for each condition. ID-1101 administration was similar to that reported in the SLD study: a 10-mg priming dose was followed by an intravenous infusion at $20 \mathrm{mg} / \mathrm{kg}$ throughout the study.

PI 3-kinase activity. Male Wistar rats received an acute injection of ID-1101 (18 mg/kg and $25 \mathrm{mg} / \mathrm{kg}$ ip for normal and type 2 diabetic animals, respectively) or insulin $(100 \mathrm{U} / \mathrm{kg}), 1 \mathrm{~h}$ after food withdrawal. Control rats were injected with vehicle (1 $\mathrm{ml}$ of saline). Fifteen minutes after injection, blood was collected for further circulating insulin measurement in plasma; then animals were killed, and liver and muscle tissues were removed for PI 3-kinase activity 
measurement, as previously described $(8,16)$. Liver and muscle were homogenized, solubilized, and ultracentrifuged. The supernatants were subjected to immunoprecipitation with anti-IRS-1. PI 3-kinase associated with IRS-1 was measured in the presence of PI and $\left[\gamma^{-33} \mathrm{P}\right]$ ATP. The incorporated radioactivity into PI was quantified with a STORM apparatus (Molecular Dynamics).

In vivo chronic treatment experiments. To assess a possible effect of ID-1101 on insulinemia, a well-known marker of insulin resistance, we chose to perform in vivo chronic treatment in normal rats as well as in two different rat models differing by the degree of their peripheral resistance to insulin: 1 ) the type 2 diabetic NA + STZ rat model, presenting an impaired glucose-induced insulin secretion together with mild hyperglycemia and insulin resistance $(18,31)$; and 2$)$ the Zucker $f a / f a$ rat, a model of obesity-associated severe insulin resistance with strong hyperinsulinemia but normoglycemia.

In a first set of experiments, 7-wk-old male Wistar rats (Iffa-Credo) were rendered type 2 diabetic by an injection of NA $(230 \mathrm{mg} / \mathrm{kg}$ ip) $15 \mathrm{~min}$ before an administration of STZ (65 mg/kg iv), according to the protocol previously described (18). After a 3-wk stabilization period, 10-wk-old type 2 diabetic NA + STZ rats presented a mild hyperglycemia together with normal insulinemia while developing progressive insulin resistance (31). These rats were treated daily with ID-1101 (50 mg/kg in $1 \mathrm{ml}$ of saline ip at 5:00 PM) for $4 \mathrm{wk}$. Control diabetic animals received intraperitoneal saline only. Concomitantly, 10 -wk-old normal Wistar rats were treated identically with ID-1101 for $4 \mathrm{wk}$.

A second set of chronic experiments was performed in obese, insulin-resistant, normoglycemic Zucker fa/fa rats. Five-week-old Zucker $f a / f a$ rats (Harlan) were housed individually with free access to food and water. After a 1-wk acclimatizing period, rats were treated daily and continuously with ID-1101 (100 mg/kg ID-1101 per os mixed with food) for $3 \mathrm{wk}$. Control diabetic animals received food only.

During these two sets of experimentations, blood samples were taken every week from the tail vessels at 10:00 AM to evaluate plasma glucose and insulin levels. Body weight and food intake were measured daily.

All procedures were carried out according to the French protocols for the care and use of experimental animals approved by the French Ministry of Agriculture, French Veterinary Services, and the Centre National de la Recherche Scientifique (CNRS). Insulin concentrations were determined by radioimmunoassay with dextran-coated charcoal separation adapted from Ref. 12, using an antiporcine insulin antibody (ICN Biochemicals, Puteaux, France) and purified rat insulin (Linco Research, St. Charles MO) as standard. Glucose concentrations were measured by the glucose oxidase method using a commercial kit (Roche Diagnostics, Meylan, France).
Statistical analysis. Statistical analyses were performed using Student's $t$-test for unpaired data or ANOVA (Statview software) for paired data. PI 3-kinase activities from multiple treatments were expressed as arbitrary densitometry units. All results are expressed as means $\pm \mathrm{SE}$, and $P<0.05$ was considered statistically significant.

\section{RESULTS}

Effect of ID-1101 during hyperinsulinemic clamp in SLD-fed rats. In the diet study, we tested four groups of rats, fed either StD or SLD diet and with or without ID-1101 during the clamp. Table 1 shows blood glucose and plasma insulin concentrations in the four groups of Sprague-Dawley rats and the GIR necessary to maintain euglycemia during the hyperinsulinemic clamp. Glycemic levels were similar under basal and hyperinsulinemic conditions, being clamped $\sim 100 \mathrm{mg} / \mathrm{dl}$. Plasma insulin concentrations were also similar in the four groups of animals, increasing from 1.25 to $7.5 \mathrm{ng} / \mathrm{ml}$. Insulin resistance caused by the SLD was clearly demonstrated in these experiments: the GIR was lower in the SLD than in the $\mathrm{StD}$ group $\left(7.06 \pm 1.48 \mathrm{vs} .11 .78 \pm 0.82 \mathrm{mg} \cdot \mathrm{kg}^{-1} \cdot \mathrm{min}^{-1}\right.$, $P<0.02)$. The infusion of ID-1101 corrected insulin resistance in the SLD rats, since the GIR was significantly higher than that observed in the absence of ID-1101 (10.99 \pm 1.07 for ID-1101 vs. $7.06 \pm 1.48 \mathrm{mg} \cdot \mathrm{kg}^{-1} \cdot \mathrm{min}^{-1}$ for control, $P<$ 0.05 ) and similar to that observed in StD rats. In Std rats, the infusion of ID-1101 did not significantly increase the GIR $\left(12.99 \pm 1.48\right.$ for ID-1101 vs. $11.78 \pm 0.82 \mathrm{mg} \cdot \mathrm{kg}^{-1} \cdot \mathrm{min}^{-1}$ for control).

Figure $1 A$ presents the GUR in the four groups of rats. Insulin induced, as expected, a clear increase in glucose utilization $(P<0.001)$. However, the SLD decreased glucose utilization during the insulin infusion period $(P<0.03)$. The stimulatory effect of insulin on the GUR was less marked in SLD rats $\left(15.60 \pm 0.87\right.$ vs. $10.68 \pm 1.42 \mathrm{mg} \cdot \mathrm{kg}^{-1} \cdot \mathrm{min}^{-1}$ with and without insulin, respectively, $P<0.02$ ) than in StD rats $\left(18.30 \pm 1.30\right.$ vs. $11.41 \pm 0.78 \mathrm{mg} \cdot \mathrm{kg}^{-1} \cdot \mathrm{min}^{-1}$ with and without insulin, respectively, $P<0.005$ ). Our most important result is that ANOVA indicated that infusion of ID-1101 during the clamp produced a significant increase in GUR in both control and SLD-fed rats, reaching, respectively, $22.14 \pm$ $1.18(+21 \%)$ and $18.60 \pm 1.81(+20 \%) \mathrm{mg} \cdot \mathrm{kg}^{-1} \cdot \mathrm{min}^{-1}(P<$ $0.02)$.

Table 1. Body weight, glycemia, insulinemia, and GIR during hyperinsulinemic euglycemic clamp

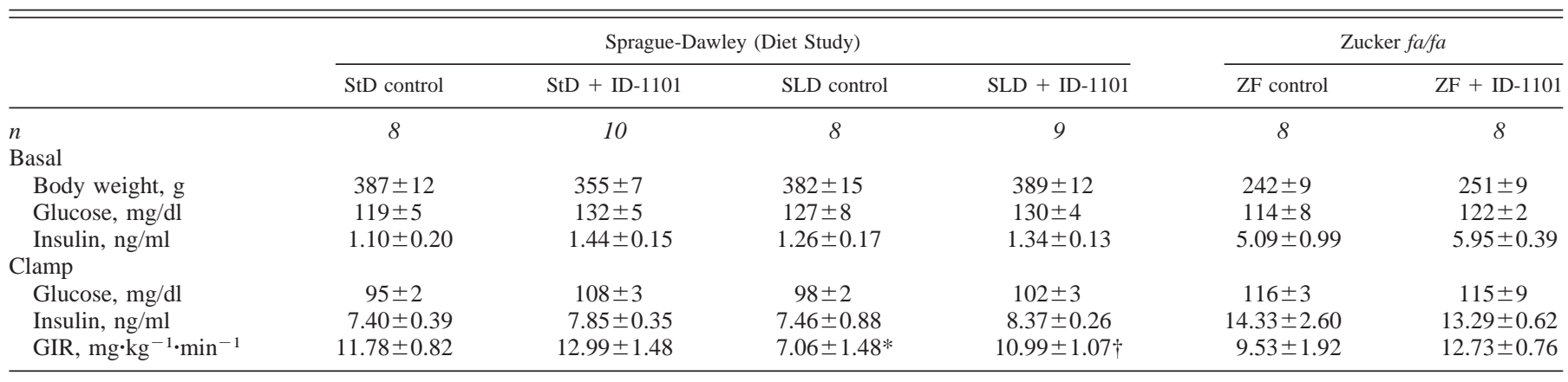

Data represent means \pm SE: $n=8-12$ rats. GIR, glucose infusion rate. Normal Sprague-Dawley rats were treated with placebo [standard diet (StD) control] or ID-1101 (StD + ID-1101). Insulin-resistant rats [Sprague-Dawley exposed to lard and sucrose (SLD) diet] were treated with placebo (SLD control) or ID-1101 (SLD + ID-1101). Zucker fa/fa rats were treated with placebo (ZF control) or ID-1101 (ZF + ID-1101). *P<0.02 for SLD vs. StD diet; $\dagger P<0.05$ for ID-1101-treated vs. untreated SLD rats. 


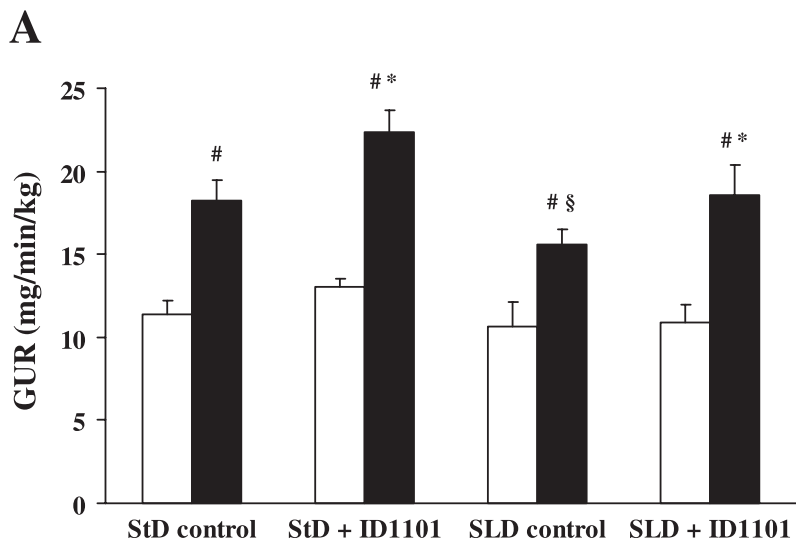

B

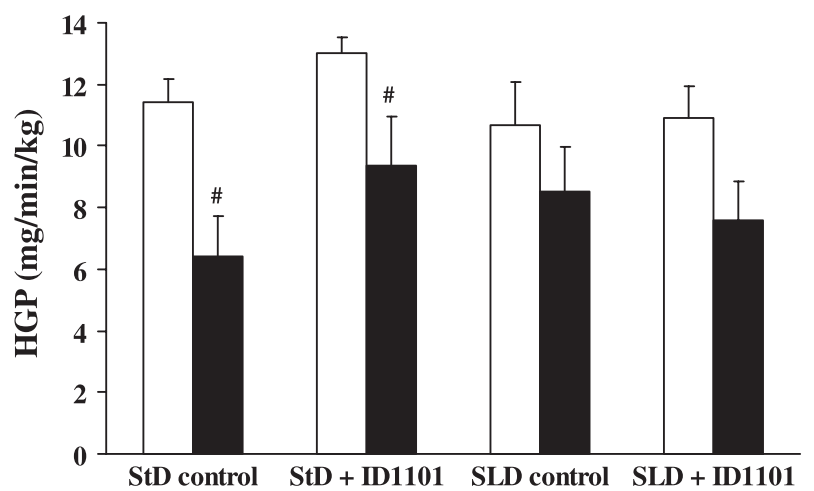

Fig. 1. Glucose utilization rate (GUR; $A$ ) and hepatic glucose production (HGP; $B$ ) under basal conditions (open bars) and during euglycemic hyperinsulinemic clamp (filled bars). Normal rats were treated with placebo [standard diet (StD) control] or ID-1101 (StD + ID-1101). Insulin-resistant rats were treated with placebo [sucrose-lipid diet (SLD) control] or ID-1101 (SLD + ID-1101). Data represent means \pm SE; $n=8-12$ rats. $* P<0.02$ for ID-1101 effect vs. control; $\# P<0.05$ for insulin vs. control; $\S P<0.03$ for SLD vs. StD alone.

Figure $1 B$ presents the HGP in the four groups of animals. Under basal conditions, HGP was identical in the four groups. As expected, insulin infusion produced a highly significant decrease in HGP in control StD rats $(6.42 \pm 1.30$ vs. $11.41 \pm$ $0.78 \mathrm{mg} \cdot \mathrm{kg}^{-1} \cdot \mathrm{min}^{-1}$, insulin vs. basal, $\left.P<0.01\right)$. This effect of insulin was blunted in control SLD rats $[8.54 \pm 1.43$ vs. $10.68 \pm 1.42 \mathrm{mg} \cdot \mathrm{kg}^{-1} \cdot \mathrm{min}^{-1}$, insulin vs. basal, not significant (NS)], as a result of hepatic insulin resistance present in this model. In rats treated with ID-1101, insulin infusion induced a slight but significant decrease in HGP (vs. basal) in the control group but not in SLD-fed rats.

Effect of ID-1101 during hyperinsulinemic clamp in Zucker $\mathrm{fa} / \mathrm{fa}$ rats. The effect of ID-1101 on glucose turnover rate was also investigated in Zucker $f a / f a$ rats. As expected, Zucker $f a / f a$ rats displayed a strong peripheral insulin resistance (insulin infusion did not induce a significant increase in GUR: $17.05 \pm$ 1.98 vs. $13.95 \pm 0.4 \mathrm{mg} \cdot \mathrm{kg}^{-1} \cdot \mathrm{min}^{-1}$, insulin vs. basal, NS) whereas a partial hepatic response to insulin is maintained $\left(7.52 \pm 0.74\right.$ vs. $13.93 \pm 0.61 \mathrm{mg} \cdot \mathrm{kg}^{-1} \cdot \mathrm{min}^{-1}$, insulin vs. basal, $P<0.01)$. The treatment with ID-1101 had no significant effect either on GIR or on GUR (Table 1 and Fig. 2A). However, ANOVA indicated that ID-1101 treatment decreased HGP in a significant way $(3.11 \pm 1.44$ vs. $7.52 \pm 0.58, \mathrm{ZF}+$ ID-1101 vs. controls, $P<0.05$; Fig. $2 B)$.
Effects of ID-1101 on PI 3-kinase activity in normal rats. To further document the acute effect of ID-1101 on insulin signaling, we measured PI 3-kinase activity in the key insulinresponsive organs of normal nonfasted rats after an acute ID-1101 administration (Fig. 3). Normal rats received a single injection of $100 \mathrm{U} / \mathrm{kg}$ insulin, $18 \mathrm{mg} / \mathrm{kg}$ ID-1101 either alone or combined with insulin, or control saline and were killed 15 min later. Insulin measurements revealed that circulating insulin level in normal rats was not modified after ID-1101 injection $(3.24 \pm 0.44 \mathrm{ng} / \mathrm{ml}$ before vs. $3.72 \pm 0.34 \mathrm{ng} / \mathrm{ml}$ after injection, NS). In both muscle and liver, insulin or ID-1101 treatment significantly $(P<0.05)$ increased PI 3-kinase activity associated with IRS-1. However, when combined, insulin and ID-1101 did not further increase the PI 3-kinase activity associated with IRS-1 in muscle or liver of normal animals.

Acute and chronic effects of ID-1101 on diabetic NA + STZ rats. To confirm the possible insulin-signaling activation by ID-1101 observed in the clamp experiments as well as on PI 3-kinase activity in normal rats, we selected two different and complementary models of insulin resistance covering a wide range of insulin resistance states, i.e., the type 2 diabetic NA + STZ rat and the obese Zucker $\mathrm{fa} / \mathrm{fa}$ rat.

The NA + STZ rat model is similar to human NIDDM in that it presents moderate hyperglycemia and insulin resistance together with an impaired but partially preserved pancreatic $\beta$-cell response to glucose. We first investigated an acute effect

A
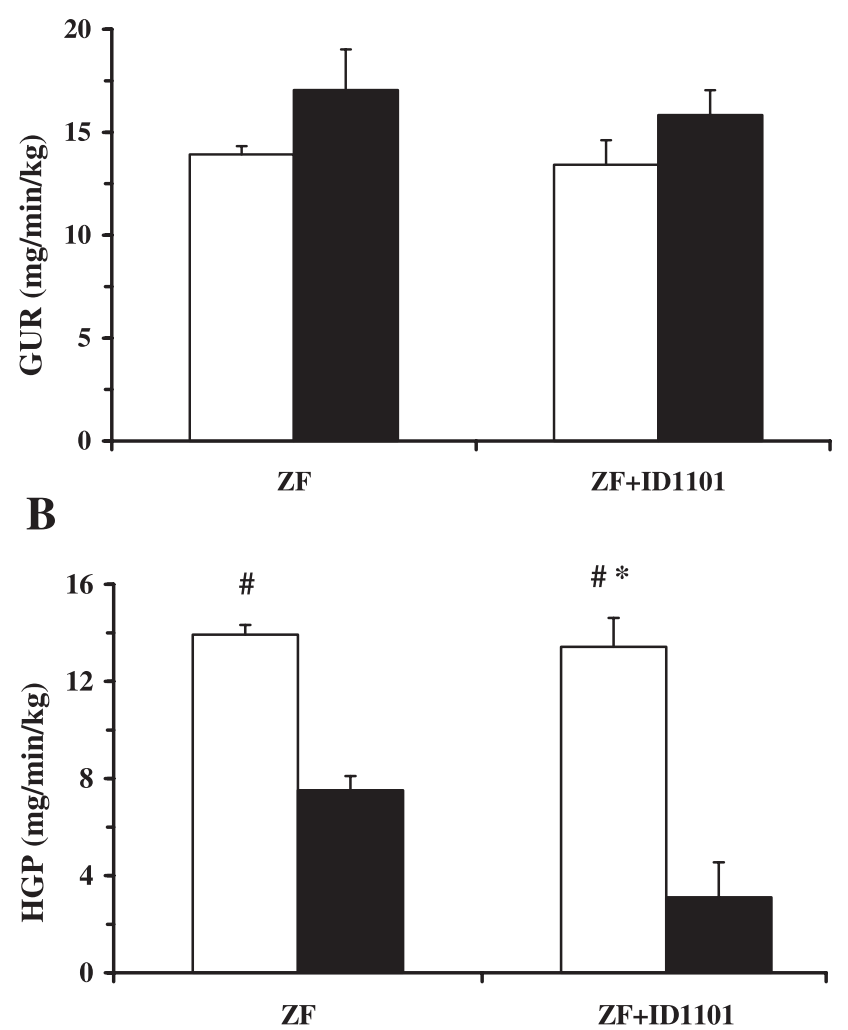

Fig. 2. GUR $(A)$ and HGP $(B)$ under basal (open bars) and during euglycemic hyperinsulinemic clamp (filled bars). Zucker fa/fa rats were treated with placebo (ZF control) or ID-1101 (ZF + ID-1101). Data represent means \pm SE; $n=8$. $\# P<0.001$ for insulin vs. control; $* P<0.05$ for ID-1101 effect vs. control. 
A

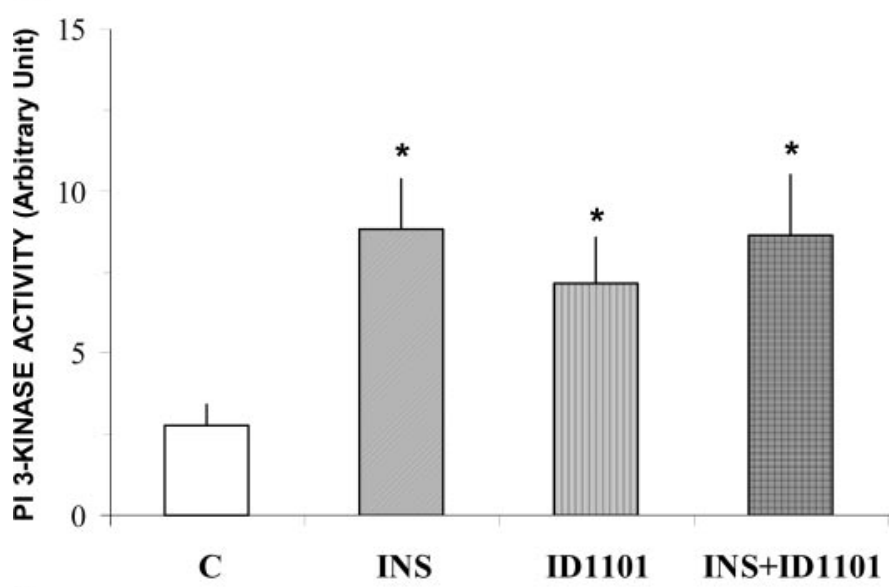

B

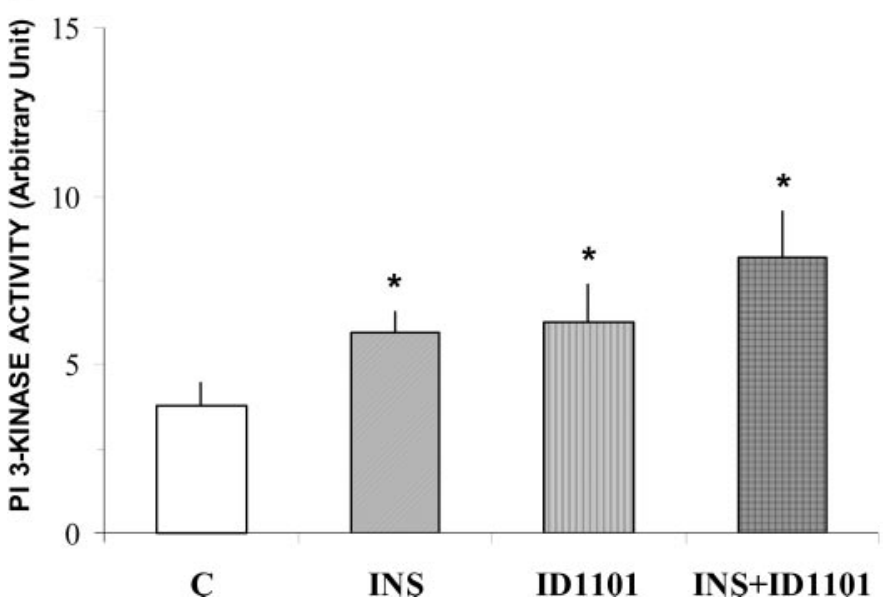

Fig. 3. Phosphatidylinositol (PI) 3-kinase activity in muscle $(A)$ and liver $(B)$ from normal rats submitted to a single injection of saline (C), insulin (INS), ID-1101, or insulin + ID-1101 (INS + ID-1101). Data represent means \pm SE; $n=4$. $* P<0.05$ vs. control group.

of ID-1101 on insulin signaling by measuring PI 3-kinase activity in muscle and liver from these diabetic rats $15 \mathrm{~min}$ after ID-1101 administration (Fig. 4). NA + STZ rats received a single injection of $100 \mathrm{U} / \mathrm{kg}$ insulin, $25 \mathrm{mg} / \mathrm{kg}$ ID-1101 either alone or combined with insulin, or control saline, and were killed 15 min later. Insulin measurements after injection revealed that ID-1101 alone did not increase basal circulating insulin level in type 2 diabetic rats $(2.79 \pm 0.47 \mathrm{ng} / \mathrm{ml}$ before vs. $2.56 \pm 0.44 \mathrm{ng} / \mathrm{ml}$ after injection, NS), as previously observed in normal rats. In muscle, insulin or ID-1101 treatment significantly increased PI 3-kinase activity associated with IRS-1. However, as previously observed in normal animals, the combination of insulin plus ID-1101 did not significantly further improve the PI 3-kinase activity associated with IRS-1 in diabetic rat muscle. It is noteworthy that the relative effect of insulin on muscle PI 3-kinase activity is more important in diabetic rats $(+338 \%)$ than in normal rats $(+217 \%)$. Moreover, in liver from diabetic animals, insulin and ID-1101 were ineffective on PI 3-kinase activity, either alone or when combined, revealing marked hepatic insulin resistance.

We then investigated a chronic functional effect of ID-1101 by use of the time course after insulinemia in NA + STZ rats treated or not with ID-1101 (Fig. 5). Administration of NA together with STZ in rats induced a clear hyperglycemia $(176.8 \pm 3.8 \mathrm{mg} / \mathrm{dl}$ in NA + STZ rats after 3 wk of diabetes vs. $139.8 \pm 2.9 \mathrm{mg} / \mathrm{dl}$ in normal rats, $P<0.01)$ but no significant change in insulinemia $(1.83 \pm 0.21 \mathrm{ng} / \mathrm{ml}$ in NA + STZ rats after $3 \mathrm{wk}$ of diabetes vs. $1.62 \pm 0.23 \mathrm{ng} / \mathrm{ml}$ in normal rats). Hyperglycemic and insulinemic values of control NA + STZ rats remained quite stable during the treatment. In this context, the 4-wk treatment with ID-1101 (50 mg/kg daily) induced a progressive and significant reduction in basal insulinemia of NA + STZ type 2 diabetic rats $(1.47 \pm 0.28 \mathrm{ng} / \mathrm{ml}$ for ID-1101-treated NA + STZ rats at the end of treatment vs. $2.20 \pm 0.19 \mathrm{ng} / \mathrm{ml}$ for placebo-treated NA + STZ rats, $P<$ 0.05 ; Fig. 5). This hypoinsulinemic effect was reversible, since 2 wk after the end of ID-1101 administration insulinemia returned to values close to basal. In addition, despite reduced plasma insulin levels, a significant decrease in hyperglycemia could also be observed at the end of the 4-wk treatment with ID-1101 $(159.2 \pm 4.1 \mathrm{mg} / \mathrm{dl}$ for ID-1101-treated NA + STZ rats vs. $172.6 \pm 3.2 \mathrm{mg} / \mathrm{dl}$ for placebo-treated NA + STZ rats, $P<0.05$; Fig. 5). No significant differences in food consumption and body weight were observed during ID-1101 treatment.

Unlike experiments performed in NA + STZ type 2 diabetic rats, those in normal rats did not show any significant effect of

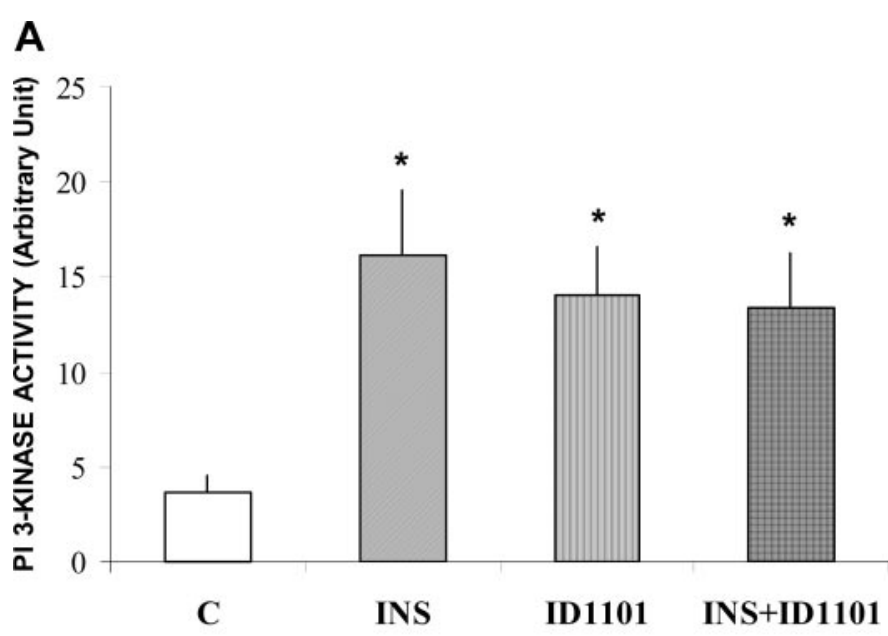

B

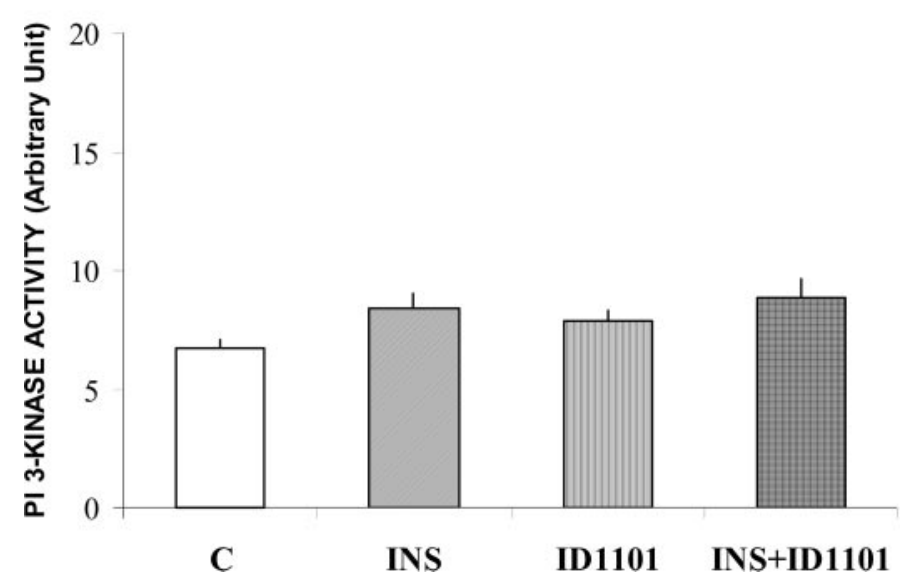

Fig. 4. PI 3-kinase activity in muscle $(A)$ and liver $(B)$ from type 2 diabetic rats submitted to a single injection of saline (C), insulin, ID-1101, or insulin + ID-1101. Data represent means $\pm \mathrm{SE} ; n=4$. ${ }^{*} P<0.05$ vs. control group. 
A

Fig. 5. Effect of chronic treatment with ID-1101 on changes of circulating basal insulin levels in type 2 diabetic nicotinamide + streptozotocin-treated (NA + STZ) rats $(A)$ and in normal rats $(B)$ and in glycemia of type 2 diabetic and normal rats $(C)$. Insulinemia before treatment was $1.62 \pm$ 0.23 and $1.75 \pm 0.13 \mathrm{ng} / \mathrm{ml}$ in diabetic rats treated with placebo and ID-1101, respectively, and $1.65 \pm 0.20$ and $1.48 \pm 0.11$ $\mathrm{ng} / \mathrm{ml}$ in normal rats treated with placebo and ID-1101, respectively. Data represent means \pm SE; $n=4$ normal rats and 8 type 2 diabetic rats. $* P<0.05$ and $* * P<0.01$ vs. control group.

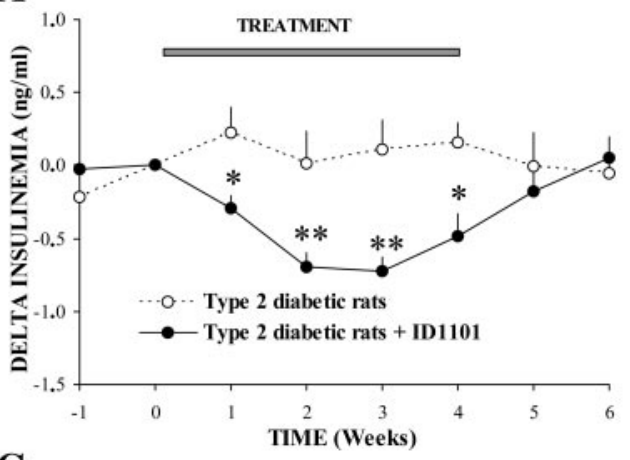

B

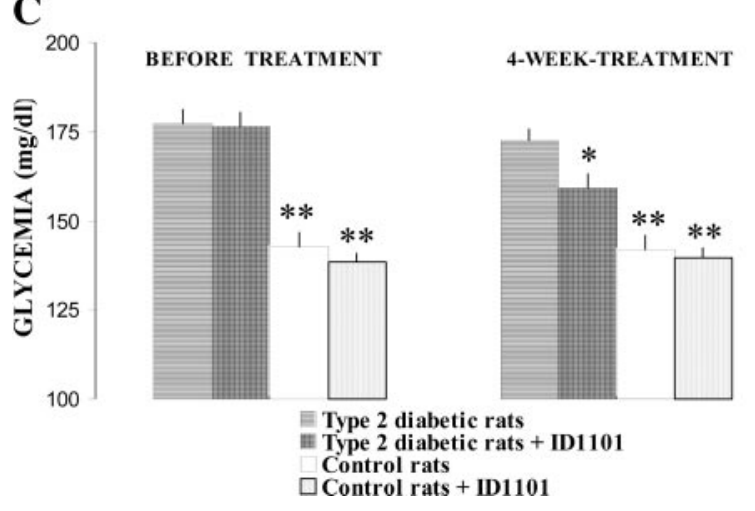

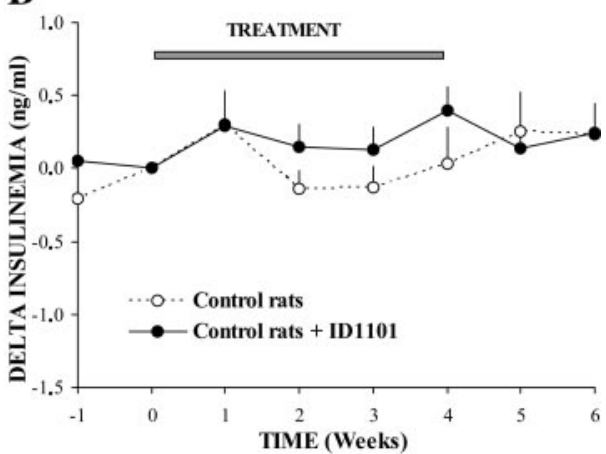

TIME (Weeks)
ID-1101 after 4 wk of treatment on glycemia $(139.7 \pm 2.8$ $\mathrm{mg} / \mathrm{dl}$ for ID-1101-treated rats vs. $142.0 \pm 3.9 \mathrm{mg} / \mathrm{dl}$ for placebo-treated rats) or on insulinemia $(1.97 \pm 0.28 \mathrm{ng} / \mathrm{ml}$ for ID-1101-treated rats vs. $1.93 \pm 0.13 \mathrm{ng} / \mathrm{ml}$ for placebo-treated rats).

Acute and chronic effects of ID-1101 on obese insulinresistant rats. Besides the type 2 diabetic NA + STZ rat model, we chose the Zucker $f a / f a$ rat, a widely used model of insulin resistance with strong hyperinsulinemia but normoglycemia. Zucker $f a / f a$ rats are well known to rapidly develop insulin resistance at hepatic and peripheral levels, as evidenced by the elevated insulinemia (Fig. 6).

We could not observe an acute effect of ID-1101 on a single intravenous injection on PI 3-kinase activity in either peripheral or hepatic tissues, which is in accord with studies showing a decrease of basal and insulin-stimulated IRS-1-associated PI 3-kinase activity from Zucker rats (data not shown). However, a 3-wk chronic treatment with ID-1101 resulted in a 2.5-fold increase in basal liver PI 3-kinase activity (data not shown; see Patent PCT/FR00/02361). Therefore, but also from our hyperinsulinemic clamp data, we were prompted to investigate the effect of a chronic administration of ID-1101 on insulin sensitivity in obese Zucker rats, using the time course following insulinemia (Fig. 6). Six-week-old obese Zucker $\mathrm{fa} / \mathrm{fa}$ rats exhibited marked hyperinsulinemia $(16.4 \pm 0.9 \mathrm{ng} / \mathrm{ml}$ for obese vs. $1.4 \pm 0.1 \mathrm{ng} / \mathrm{ml}$ for lean littermates, $P<0.001$ ) together with normoglycemia $(96.9 \pm 2.3 \mathrm{mg} / \mathrm{dl}$ for obese vs. $91.1 \pm 3.2 \mathrm{mg} / \mathrm{dl}$ for lean littermates, NS). During the 3 -wk experiment, hyperinsulinemia significantly increased in obese rats (from $15.2 \pm 3.6 \mathrm{ng} / \mathrm{ml}$ to $21.6 \pm 5.7 \mathrm{ng} / \mathrm{ml}$, $+42 \%$ ) whereas glycemia remained normal, showing that endocrine pancreatic hyperactivity was able to compensate for and overcome insulin resistance. A 3-wk oral treatment with ID-1101
(100 mg/kg daily) significantly reduced hyperinsulinemia compared with the progressive increase observed in control obese Zucker rats $(-1.1 \pm 1.3 \mathrm{ng} / \mathrm{ml}$ at the end vs. beginning of treatment in ID-1101-treated obese Zucker rats vs. $+6.9 \pm 3.5$ $\mathrm{ng} / \mathrm{ml}$ in control obese Zucker rats, $P<0.05)$. In the same conditions, metformin ( $200 \mathrm{mg} / \mathrm{kg}$ daily) also totally prevented $(+0.1 \pm 2.6 \mathrm{ng} / \mathrm{ml}$ at the end vs. beginning of treatment; data not shown) the progressive increase in insulinemia observed in control obese rats during the period of treatment. It is also interesting to note that ID-1101 treatment modified neither plasma glucose levels nor food consumption and weight gain in obese Zucker rats.

\section{DISCUSSION}

The present study shows that the amino acid ID-1101 is able to exert insulin-sensitizing effects independently of its insulinotropic action. Using the gold standard method, i.e., the hyperinsulinemic clamp, we could first demonstrate that ID1101 is able to improve insulin resistance by increasing peripheral glucose uptake in sucrose-lipid-fed rats or by decreasing hepatic glucose output in Zucker $f a / f a$ rats. These data were then confirmed by experiments showing that an acute in vivo injection of ID-1101 activates IRS-1-related PI 3-kinase activity in insulin-sensitive tissues, provided that insulin alone is also effective. Finally and most importantly, we could characterize these potential insulin-sensitizing and antidiabetic properties in chronic in vivo studies by use of two rat models differing by the degree of their insulin resistance: first, NA + STZ diabetic rats, a model close to human type 2 diabetes with impaired $\beta$-cell function and mild insulin resistance (18), and second, obese Zucker fa/fa rats, a model of severe insulin 
A

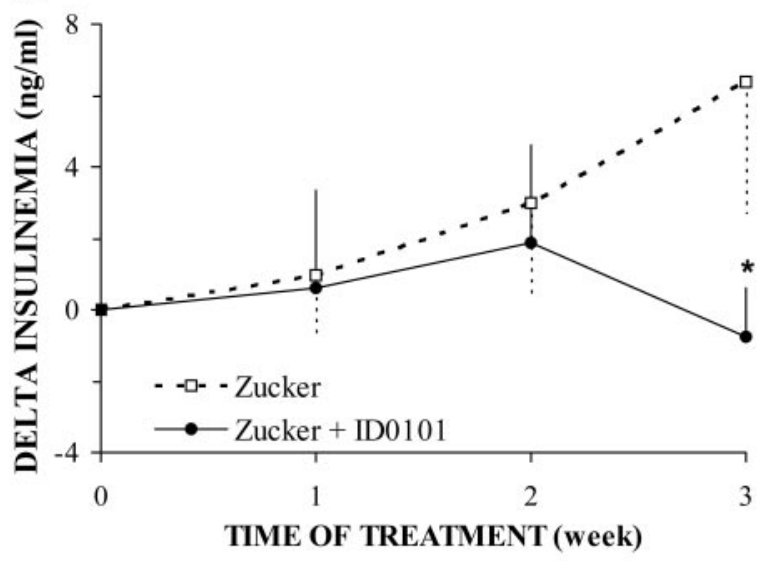

B

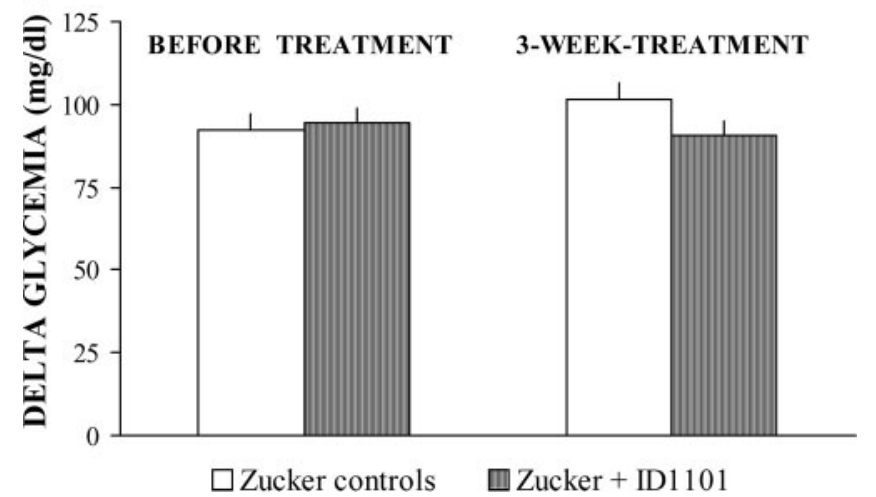

Fig. 6. Effect of chronic treatment with ID-1101 on changes of circulating insulin $(A)$ and glucose $(B)$ levels in insulin-resistant obese Zucker $f a / f a$ rats. Data represent means $\pm \mathrm{SE} ; n=7$. Insulinemia before treatment was $15.2 \pm$ 3.5 and $16.4 \pm 2.7 \mathrm{ng} / \mathrm{ml}$ in Zucker rats treated with placebo and ID-1101, respectively. $* P<0.05$ vs. control group.

resistance compensated by very high levels of circulating insulin.

ID-1101 is an amino acid exclusively present in fenugreek, a plant traditionally used to treat diabetes. After isolation and purification of this amino acid, we discovered that ID-1101 displays an interesting insulinotropic activity with characteristics that differ from those of related compounds, i.e., branchedchain amino acids $(6,27)$. Besides ID-1101's insulin-releasing activity, antidiabetic properties of fenugreek extracts have also been attributed to fiber-induced delayed intestinal glucose absorption and more recently to unidentified insulin-sensitizing effects $(24,25)$. In this respect, branched-chain amino acids are well known to modulate the insulin-signaling pathway and especially leucine, which has recently been shown to exert both positive and negative signals on insulin-stimulated protein and glucose metabolism (21). So we were interested in investigating a possible insulin-sensitizing effect of this amino acid, all the more because ID-1101 is a vegetal, nonproteinogen branched-chain amino acid, never found in mammalian tissues.

The insulin-sensitizing effect of ID-1101 was first evidenced using euglycemic hyperinsulinemic clamps. In sucrose-lipidfed insulin-resistant rats, the glucose infusion rate required to maintain euglycemia under hyperinsulinemic conditions was much higher in the presence of ID-1101 than in the absence of the molecule and was in fact identical to that observed in control rats. Indeed, ID-1101 significantly increased the peripheral glucose utilization rate in insulin-resistant rats. Hepatic glucose production was decreased by insulin in normal rats, and this effect was blunted in sucrose-lipid-fed rats, suggesting that, in this model, resistance to insulin occurs especially at the hepatic level. Under such drastic conditions, ID-1101 was, as insulin, unable to decrease hepatic glucose production.

Hyperinsulinemic clamp studies were also performed on obese Zucker $\mathrm{fa} / \mathrm{fa}$ rats. A very severe insulin resistance was present at the peripheral level, as shown by the inability of insulin to affect the glucose utilization rate, which probably also accounts for ID-1101's inefficiency. On the other hand, liver presents a lower degree of insulin resistance, as reflected by the persistence of a significant effect of insulin; in this tissue, ID-1101 is able to further reduce hepatic glucose production. Taken together, these data strongly suggest that the amino acid is able to improve insulin resistance in hepatic or peripheral tissues provided that tissue sensitivity to the hormone is partially preserved, further suggesting that ID-1101 is an insulin sensitizer.

This insulin-sensitizing action of ID-1101 is also strongly supported by the activation of PI 3-kinase activity in vivo in rats. In normal rats, a single injection of ID-1101 activates the PI 3-kinase associated to IRS-1 in both liver and muscle. In this respect, amino acids, particularly the classical branched-chain amino acids leucine and isoleucine, are well known to modulate insulin action $(3,19,21)$ and to exert concurrent bidirectional effects in hepatocytes and myocytes; indeed, they are able on the one hand to stimulate key insulin signal transduction pathway intermediates of protein synthesis, whereas on the other hand they inhibit early steps in insulin signaling critical for glucose transport, including PI 3-kinase activity (21). This contrasts with the stimulatory effect of ID-1101 on PI 3-kinase activity that we observed in normal rats, suggesting that ID1101 differs markedly from other natural branched-chain amino acids.

This effect of ID-1101 in normal rats very likely results from a direct effect on target tissues, since a single injection of ID-1101 did not increase circulating insulin levels. This also agrees with our previous in vitro and in vivo studies showing that ID-1101's insulinotropic effect appears only in the presence of stimulating and not at basal glucose concentrations $(5,27)$.

The effect of ID-1101 on PI 3-kinase activity was also studied in a model of diabetes with insulin resistance, the $\mathrm{NA}+\mathrm{STZ}$ diabetic rats. STZ-induced diabetic rats are known to develop hepatic and peripheral insulin resistance (34). We used a combined administration of NA and STZ to afford partial protection against the $\beta$-cytotoxic effect of STZ and to induce a diabetic state close to human type 2 diabetes (18). In addition, these rats, despite their relatively modest insulin resistance compared with Zucker rats, are slightly hyperglycemic, which makes them more suitable, because hyperglycemia could have deleterious effects on insulin receptor and postreceptor signaling. In type 2 diabetic NA + STZ rats, insulin increased muscle PI 3-kinase activity to a greater level than in normal rats. These data are in good agreement with previous studies concluding that STZ-diabetic rats exhibit, compared with controls, markedly elevated basal and insulin-stimulated PI 3-kinase activity in anti-IRS-1 immunoprecipitates (11). In 
this context, it must be emphasized that the stimulating effect of an acute injection of ID-1101 on muscle PI 3-kinase activity occurs independently of an increase in circulating insulin levels. The absence of ID-1101-stimulated insulin secretion in these mildly hyperglycemic rats has been previously explained by glucose toxicity and by the right shift of the glucoseinduced insulin response sigmoid curve (5); it argues in favor of a direct effect of the amino acid on peripheral tissues.

As concerns the ineffectiveness of ID-1101 on liver PI 3-kinase in NA + STZ rats, such a failure could be related to an increased basal activity in this model, all the more since both insulin and ID-1101 are effective in normal animals in which basal activity is lower. Furthermore, it is noteworthy that, as observed in glucose turnover studies, ID-1101's stimulating effect on PI 3-kinase also clearly depends on a preserved response to insulin. In this respect, in the Zucker rats, the apparently discordant data concerning the ineffectiveness of a single intravenous ID-1101 injection on liver PI 3-kinase activity and hyperinsulinemic clamp experiments pointing to an effect on hepatic glucose production could be due to a longer-lasting administration of ID-1101 in the latter and/or different insulin levels present in these two experimental conditions. Nevertheless, the sole effects of ID-1101 on muscle PI 3-kinase activity in type 2 diabetic rat, as well as its effect on liver PI 3-kinase activity in Zucker rats, are of great therapeutic potential: they might explain 1 ) the decrease in hyperglycemia in type 2 diabetic rats chronically treated with ID-1101 together with the simultaneous significant reduction of insulinemia (5), and 2) the insulin-sparing activity of ID-1101 in obese insulin-resistant Zucker rats.

In this respect, besides the results we obtained in acute conditions, our data in chronic in vivo treatments in type 2 diabetic NA + STZ rats as well as in obese Zucker rats reveal a clear hypoinsulinemic and insulin-sparing effect of ID-1101. Interestingly, the hypoinsulinemic effect of ID-1101 observed in type 2 diabetic rats and in obese normoglycemic rats is not present in normal rats. The NA + STZ rat model is characterized by defective glucose-stimulated insulin secretion and progressive insulin resistance (31), which could be responsible for and partly explain the selective effect of ID-1101 in type 2 diabetic animals but not in normal ones. Also of importance is that the insulin-sensitizing effect of ID-1101 occurs as well in a more drastic model of insulin resistance, as evidenced by the insulin-sparing effect of ID-1101 in the obese normoglycemic Zucker $f a / f a$ rat $(26,30)$. Taken together, these data emphasize the insulin-sensitizing role of ID-1101, which is able to decrease insulinemia together with glycemia in type 2 diabetic rats and to counteract the progressive worsening of insulin resistance that develops in obese $f a / f a$ animals, as reflected by the increase in hyperinsulinemia in nontreated animals.

Finally, the ability of ID-1101 to activate pancreatic $\beta$-cell function as well as insulin signaling, which emerges from our present and previous studies $(5,6,27)$, raises the question of the possible existence of a unique mechanism that could account for both effects. There is considerable uncertainty about the autocrine effects of insulin on pancreatic $\beta$-cells; numerous studies have yielded conflicting data, reporting that insulin either does not affect $(10,28)$, inhibits $(2,20,22)$, or stimulates insulin secretion (4). In this context, our findings concerning the ability of ID-1101 to activate both insulin signaling and insulin secretion suggest that ID-1101 could also stimulate pancreatic $\beta$-cells through a mechanism related to PI 3-kinase. The recently demonstrated ability of rosiglitazone to enhance insulin secretion in a PI 3-kinase-dependent way supports such a suggestion (33).

In conclusion, we demonstrate that the antidiabetic properties of ID-1101 result not only from its previously demonstrated insulinotropic action but also from extrapancreatic insulin-sensitizing effects. These insulin-sensitizing effects involve the early steps of insulin signaling, downstream from the binding of insulin to its receptor. By improving the insulin response to glucose in the $\beta$-cells and enhancing insulin activation of IRS/PI 3-kinase in extrapancreatic tissues, ID-1101 acts on the two essential dysfunctions of type 2 diabetes and thus appears as the potential leader of a novel class of antidiabetic agents.

\section{ACKNOWLEDGMENTS}

We thank S. Dietz and M. Tournier for excellent technical assistance. We also thank Prof. P. Masiello (University of Pisa, Italy) and Dr. N. Chapal (INNODIA S.A., Montpellier, France) for helpful discussions and expert technical assistance with diabetic rats.

\section{GRANTS}

This work was supported by INNODIA S.A. (France).

\section{DISCLOSURES}

The results of this study have led to a patent (Ribes G, Taouis M, Petit P, Sauvaire Y, Broca C, and Pau B. Use of amino acids for making medicines for treating insulin resistance. Patent no. PCT/FR00/02361, August 23, 2000). The patent is held by the Centre National de la Recherche Scientifique and the Institut National de la Recherche Agronomique, both of Paris, France.

\section{REFERENCES}

1. Agheli N, Kadir M, Berni-Canani S, Petitjean E, Boussairi A, Luo J, Bornet F, Slama G, and Rizkalla SW. Plasma lipids and fatty acid synthase activity are regulated by short-chain fructo-oligosaccharides in sucrose-fed insulin-resistant rats. J Nutr 128: 1283-1288, 1998.

2. Ammon HP and Verspohl E. Pyridine nucleotides in pancreatic islets during inhibition of insulin release by exogenous insulin. Endocrinology 99: 1469-1476, 1976.

3. Anthony JC, Anthony TG, Kimball SR, and Jefferson LS. Signaling pathways involved in translational control of protein synthesis in skeletal muscle by leucine.J Nutr 131: 856S-860S, 2001.

4. Aspinwall CA, Lakey JR, and Kennedy RT. Insulin-stimulated insulin secretion in single pancreatic beta cells. J Biol Chem 274: 6360-6365, 1999.

5. Broca C, Gross R, Petit P, Sauvaire Y, Manteghetti M, Tournier M, Masiello P, Gomis R, and Ribes G. 4-Hydroxyisoleucine: experimental evidence of its insulinotropic and antidiabetic properties. Am J Physiol Endocrinol Metab 277: E617-E623, 1999.

6. Broca C, Manteghetti M, Gross R, Baissac Y, Jacob M, Petit P, Sauvaire Y, and Ribes G. 4-Hydroxyisoleucine: effects of synthetic and natural analogues on insulin secretion. Eur J Pharmacol 390: 339-345, 2000.

7. DeFronzo RA. The triumvirate: $\beta$-cell, muscle, liver a collusion responsible for NIDDM. Diabetes 37: 667-687, 1988.

8. Dupont J, Derouet M, Simon J, and Taouis M. Effect of nutritional state on the formation of a complex involving insulin receptor IRS-1, the 52 $\mathrm{kDa}$ Src homology/collagen protein (Shc) isoform and phosphatidylinositol 3'-kinase activity. Biochem J 335: 293-300, 1998.

9. Fluteau-Nadler S, Rizkalla SW, Luo J, Guerre-Millo M, Luo J, Bruzzo F, and Slama G. Regulation of glucose transporters in muscle and adipocytes of insulin resistant rats: effects of n-3 poly- and monounsatured fatty acids (Abstract). Diabetologia 39: A173, 1996.

10. Gao Z, Konrad RJ, Collins H, Matschinsky FM, Rothenberg PL, and Wolf BA. Wortmannin inhibits insulin secretion in pancreatic islets and beta-TC3 cells independent of its inhibition of phosphatidylinositol 3-kinase. Diabetes 45: 854-862, 1996. 
11. Giorgino F, Logoluso F, Davalli AM, Napoli R, Laviola L, Hirshman MF, Horton ES, Weir G, and Smith RJ. Islet transplantation restores normal levels of insulin receptor and substrate tyrosine phosphorylation and phosphatidylinositol 3-kinase activity in skeletal muscle and myocardium of streptozocin-induced diabetic rats. Diabetes 48: 801-812, 1999.

12. Herbert V, Laws KS, Gottlieb CW, and Bleicher SJ. Coated charcoal immunoassay of insulin. J Clin Endocrinol Metab 25: 1375-1365, 1965.

13. Kahn CR. Insulin receptors and insulin signaling in normal and disease states. In: International Textbook of Diabetes Mellitus (2nd ed.), edited by Alberti KGMM, Zimmet P, DeFronzo RA, and Keen H. Philadelphia, PA: Lippincott-Raven, 1997, p. 437-467.

14. Kahn SE and Porte D. Islet dysfunction in non insulin-dependent diabetes mellitus. Am J Med 85: 4-8, 1988

15. Kergoat $\mathbf{M}$ and Portha $\mathbf{B}$. In vivo hepatic and peripheral insulin sensitivity in rats with non-insulin-dependent diabetes induced by streptozocin: assessment with the insulin-glucose clamp technique. Diabetes 34: 1120 1126, 1985.

16. Levy-Toledano R, Taouis M, Blaettler DH, Gorden P, and Taylor SI. Insulin-stimulated activation of phosphatidyl inositol 3-kinase due to direct binding of the $\mathrm{p} 85$ subunit to the C-terminus of the insulin receptor in intact cells. J Biol Chem 269: 31178-31182, 1994.

17. Magnan C, Gilbert M, and Kahn BB. Chronic free fatty acid infusion in rats results in insulin resistance but no alteration in insulin-responsive glucose transporter levels in skeletal muscle. Lipids 31: 1141-1149, 1996.

18. Masiello P, Broca C, Gross R, Roye M, Manteghetti M, Hilaire-Buys D, Novelli M, and Ribes G. Experimental NIDDM: development of a new model in adult rats administered streptozotocin and nicotinamide. Diabetes 47: 224-229, 1998.

19. May ME and Buse MG. Effects of branched-chain amino acids on protein turnover. Diabetes Metab Rev 5: 227-245, 1989.

20. Pace CS, Matschinsky FM, Lacy PE, and Conant S. Electrophysiological evidence for the autoregulation of beta-cell secretion by insulin. Biochim Biophys Acta 497: 408-414, 1977.

21. Patti ME, Brambilla E, Luzi L, Landaker EJ, and Kahn CR. Bidirectional modulation of insulin action by amino acid. J Clin Invest 101: 1519-1529, 1998.

22. Persaud SJ, Asare-Anane H, and Jones PM. Insulin receptor activation inhibits insulin secretion from human islets of Langerhans. FEBS Lett 510: 225-228, 2002.
23. Previs SF, Withers DJ, Ren JM, White MF, and Shulman GI. Contrasting effects of IRS-1 versus IRS-2 gene disruption on carbohydrate and lipid metabolism in vivo. J Biol Chem 275: 38990-38994, 2002.

24. Raju J, Gupta D, Rao AR, Yadava PK, and Baquer NZ. Trigonella foenum graecum (fenugreek) seed powder improves glucose homeostasis in alloxan diabetic rat tissues by reversing the altered glycolytic, gluconeogenic and lipogenic enzymes. Mol Cell Biochem 224: 45-51, 2001.

25. Ribes G, Sauvaire Y, Da Costa C, Baccou JC, and LoubatieresMariani MM. Antidiabetic effects of subfractions from fenugreek seeds in diabetic dogs. Proc Soc Exp Biol Med 182: 159-166, 1986.

26. Rohner-Jeanrenaud F, Proietto J, Ionescu E, and Jeanrenaud B. Mechanism of abnormal oral glucose tolerance of genetically obese fa/fa rats. Diabetes 35: 1350-1355, 1986.

27. Sauvaire Y, Petit P, Broca C, Manteghetti M, Baissac Y, Gross R, Roye M, Leconte A, Gomis R, and Ribes G. 4-Hydroxyisoleucine, a novel amino acid potentiator of insulin secretion. Diabetes 47: 206-210, 1998.

28. Schatz H and Pfeiffer EF. Release of immunoreactive and radioactively prelabelled endogenous (pro)-insulin from isolated islets of rat pancreas in the presence of exogenous insulin. J Endocrinol 74: 243-249, 1977.

29. Scott PH, Brunn GJ, Kohn AD, Roth RA, and Lawrence JC. Evidence of insulin-stimulated phosphorylation and activation of the mammalian target of rapamycin mediated by a protein kinase B signaling pathway. Proc Natl Acad Sci USA 95: 7772-7777, 1998.

30. Shafrir E. Diabetes in animals. In: Diabetes Mellitus: Theory and Practice, edited by Rifkin H and Porte D Jr. New York: Elsevier, 1990, p. 299-340.

31. Taouis M, Broca C, Masiello P, Roye M, Manteghetti M, Derouet M, Gross R, and Ribes G. Delayed occurrence of insulin resistance in a new experimental model of NIDDM (Abstract). Diabetologia 41: A198, 1998.

32. White MF. The insulin signalling system and the IRS proteins. Diabetologia 40: S2-S17, 1997.

33. Yang C, Chang TJ, Chang JC, Liu MW, Tai TY, Hsu WH, and Chuang LM. Rosiglitazone (BRL 49653) enhances insulin secretory response via phosphatidylinositol 3-kinase pathway. Diabetes 50: 2598 2602, 2001.

34. Youn HJ, Kim JK, and Buchanan TA. Time course of changes in hepatic and skeletal muscle insulin action and GLUT4 protein in skeletal muscle after STZ injection. Diabetes 43: 564-571, 1994. 